\title{
Will the liquid biopsy replace traditional hematopathology?
}

\author{
J. H. van Krieken ${ }^{1}$
}

Published online: 19 July 2017

(C) Springer-Verlag GmbH Germany 2017

In this issue's literature review [1], I end with the remark that is the title of this editorial, based on work by Rossi et al. [2]. They show that deep sequencing of cell-free DNA obtained from the blood provides molecular information on a lymphoma of a patient that is not only an accurate reflection of what was obtained from a traditional biopsy but even goes beyond that. It was possible to have repeated blood testing over time and detect resistance mutations, something not feasible by tissue biopsies. Of course, these findings need to be confirmed, in larger groups of patients, in different laboratories, but I have no doubt that they will be. In fact, for lung cancer, blood testing has already partly replaced tissue biopsies. I question therefore the future of hematopathology in its present form. However, I have also great confidence that the role of hematopathologists will remain, and may even become larger, provided that hematopathologists will adapt to the new technologies and possibilities. Since in the past they have always done so, I see no reason they will not do so in the future.

I have always seen hematopathology as the bridge between enormous amounts of information and the hematologist. Next to the microscope, the telephone was and is the most important instrument in hematopathology. With the increasing amatory available to treat patients with hematological malignancies on the one hand and the huge amount of data that is derived from tissue biopsy (and indeed increasingly blood tests) on the other, there is a real need for an interpreter; an interpreter who understands both sides and has a good understanding of the

J. H. van Krieken

Han.vanKrieken@radboudumc.nl

1 Department of Pathology, Radboud University Medical Centre, P.O. Box 9101, 6500 HB Nijmegen, The Netherlands possibilities and limitation of the array of tests, including morphology, immunohistochemistry, molecular data, and the clinic. It is already long known that a BRAF mutation in a melanoma has a complete different meaning than one in colorectal cancer or hairy cell leukemia; of course, a molecular blood test cannot make the difference. Another example is provided in the same literature review: MYD88 mutation can occur in a series of different lesions in patients with IgM monoclonal gammopathy; yet, the mutation is not the driver of the disease let alone that it can be used to make a diagnosis [3].

I believe that the well-trained hematopathologist is in the best position to integrate the data, but it is important that he or she has indeed the complete knowledge base and the access to the information. I know that there are already boundary battles over who is responsible for genetic data, for the development of reliable deep sequencing approaches in blood samples, etc. Never have these battles benefitted patients and always they are waste of time, energy, and money.

I do hope that the fast development of precision medicine will radically alter the role of the hematopathologists and they are ready to take the challenge on, for the benefit of patients.

\section{References}

1. Han van Krieken J (2017) New developments in the pathology of malignant lymphoma. A review of the literature published from January to April 2017. J Hematopathol

2. Rossi D, Diop F, Spaccarotella E, Monti S, Zanni M, Rasi S, Deambrogi C, Spina V, Bruscaggin A, Favini C, Serra R, Ramponi A, Boldorini R, Foà R, Gaidano G (2017) Diffuse large B-cell lymphoma genotyping on the liquid biopsy. Blood 129:1947-1957

3. Cao XX, Meng Q, Cai H, He TH, Zhang CL, Su W, Sun J, Li Y, Xu W, Zhou DB, Li J (2017) Detection of MYD88 L265P and WHIMlike CXCR4 mutation in patients with IgM monoclonal gammopathy related disease. Ann Hematol 96:971-976 